\title{
Analysis of the Spatial and Temporal Variability of Irrigated Maize Yield
}

\author{
J.R. Marques da Silva \\ Departamento de Engenharia Rural, Universidade de Évora, Apartado 94, 7002-554 Évora, Portugal; e-mail: jmsilva@uevora.pt
}

(Received 19 May 2005; accepted in revised form 14 March 2006; published online 11 May 2006)

\begin{abstract}
The quantitative analysis of the yield of seven irrigated plots of land sown with maize was carried out over a period of $3 \mathrm{yr}$ in order to determine the spatial and temporal variability. The methodology used was based on: inter-annual analysis of yield, which quantifies the overall difference in production from $1 \mathrm{yr}$ to the next; and temporal variance, which indicates the variability of yield at a given point over time. The results show that even with irrigated crops, where production factors are generally subject to high degree of control, there is a high degree of inter-annual variability, becoming less marked over time. These results enable an investment risk map associated with a given crop and a given plot to be drawn; they also enable it to be shown that the sum of the yield for stable zones for each field decreases as field area increases, indicating that the greater the length of the centre pivot irrigator used, the lower the temporal stability of yield. The most stable yields are associated with an average distance of about $15 \mathrm{~m}$ from the flow lines; finally, the results show that forecasting for future years is extremely difficult owing to the fact that the temporal variability of yield may vary between 1 and $8 \mathrm{t} /$ ha.

(C) 2006 IAgrE. All rights reserved

Published by Elsevier Ltd
\end{abstract}

\section{Introduction}

Before taking any decision, all farm managers would like to have an indication of the risk associated with the investment to be made. In most cases, the risk associated with a given farming investment is not fully known and most managers take decisions on the basis of intuitive guesses, very often on the basis of experience gained following successful investments. When commercial yield mapping began in the early 1990s, the conventional wisdom was that productive stability would be constant, that is, the yield of certain parts of a given plot of land would always be low while that of other parts of the same plot would always be high. This principle was linked to the idea that permanent soil characteristics would always behave in the same way, year in year out. This concept was even more entrenched with regards to irrigated crops, as the degree of control of production factors was even greater than that for dry-field crops. Various authors have developed different types of methods for the analysis of this spatial and temporal variability: Larscheid and Blackmore (1996); Swindell (1997); Lark and Stafford (1996a, 1996b); and Panneton et al.
(2001). Panneton and Brouillard (2001) and, more recently, Blackmore et al. (2003) have used a similar technique for identifying the sites where production is stable over time and sites where it is unstable.

If the inter-annual yield trend of yield were to show only a slight degree of variability, yield maps would provide an excellent tool as the spatial distribution of yield in subsequent years could be predicted. In order to test this temporal stability, a forecast has to be made comparing the different years with each other.

Blackmore et al. (2003) encountered great difficulty in establishing a temporal threshold for stability and instability for the crop studied. They found that spatial trends over time were not stable. Instead, the spatial trends in all of the fields studied became less pronounced than the variability found in individual years.

The main objective of this study was to evaluate, in an irrigated crop, the possibility of yield maps forecasting the yield pattern for the following year. This study addressed the main following question: How can a crop be spatially managed in accordance with its historical records or with its needs in real time? 